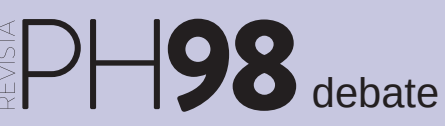

¿Hay patrimonio sin comunidad? Despoblamiento, turistificación y patrimonio cultural

coordina Jaime Jover Báez

\title{
Cooperativas como política habitacional para los centros históricos ¿Una alternativa frente al despoblamiento?
}

\author{
Alejandra González Biffis | Comisión Nacional de Investigaciones Científicas y Tecnicas, Centro de Investigaciones Urbanas y \\ Territoriales, Universidad Nacional de La Plata (Argentina)
}

URL de la contribución <www.iaph.es/revistaph/index.php/revistaph/article/view/4448>

Las políticas habitacionales deben atender la gran complejidad que representa intervenir dicha temática en el contexto de los centros históricos, intentando articular por un lado la revalorización y conservación del valioso patrimonio construido que concentran, con la conservación y reconquista del invaluable patrimonio social.

Con este fin, en Uruguay se crea hace aproximadamente cinco décadas la Federación Uruguaya de Cooperativas de Vivienda por Ayuda Mutua (FUCVAM), un movimiento social reconocido en América Latina, referente del cooperativismo, que ha apostado por una economía social y un modelo comunitario del habitar que agrupa 363 cooperativas habitadas y que, junto a la Federación de Cooperativas de Vivienda de Usuarios por Ahorro Previo (FECOVI), provee vivienda a 25.000 familias. El sistema que aplican propone una alternativa que contribuye al acceso a la vivienda popular y a la construcción de comunidad (VALENZUELA, 2018).

El centro histórico de la ciudad uruguaya de Montevideo, la Ciudad Vieja, no ha estado exento del fenómeno del despoblamiento que atañe a numerosos centros históricos y ha perdido una gran cantidad de población a causa de la crisis económica de los años 50. La política de recuperación de construcciones históricas o espacios vacantes para uso residencial ha sido firme y ha otorgado prioridad a familias populares originarias del sector, facilitando el acceso a la vivienda con miras a fomentar el repoblamiento, defendiendo un hábitat policlasista e integrado. Con este fin, se ha empleado el sistema de cooperativas de viviendas, que han actuado restaurando edificios patrimoniales degradados, que habían tenido originalmente diversas funciones, o han llevado adelante la construcción de obra nueva.
Una de las primeras cooperativas en intervenir fue CICOVICI 1, 2 y 3, con 34 viviendas. Posteriormente con esta organización se han creado otras cooperativas como Federación de Cooperativas de Usuarios por Ahorro Previo (FECOVI), Puerto Fabini, y Mujefa ("Mujeres Jefas de familia"). Estos proyectos han intentado promover identidad y apropiación de barrios antiguos y marginados de la ciudad, limitando el avance de procesos de gentrificación que usualmente suelen afectar a las áreas de gran valor patrimonial de las ciudades.

La Intendencia de Montevideo facilita el acceso a la tierra a través de licitaciones para la adquisición de terrenos. Las cooperativas permiten que un mismo inmueble genere varias unidades habitacionales, exoneradas de contribución inmobiliaria. Las tierras (con edificaciones pendientes de remodelar o demoler) son vendidas a las cooperativas con subsidios altos y largos plazos, sin intereses para facilitar el acceso.

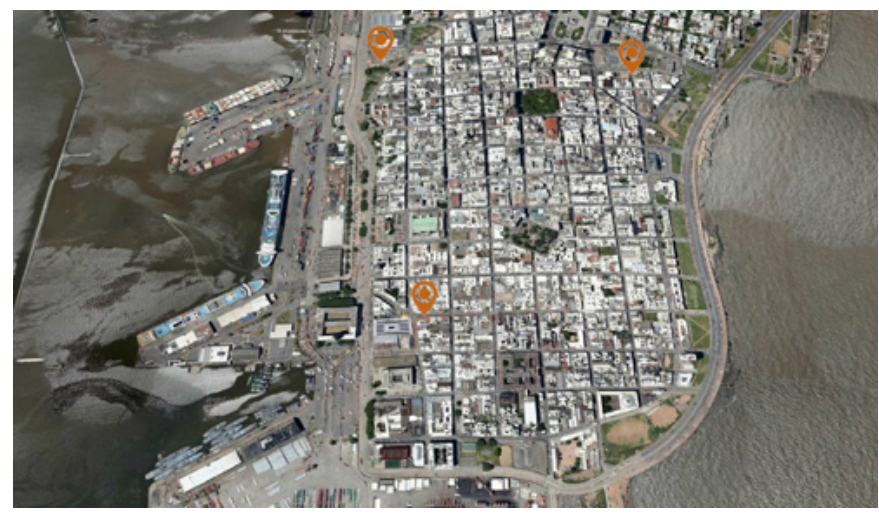

Localización aérea de las obras de la Ciudad Vieja | foto Federación de Cooperativas de Vivienda de Usuarios por Ahorro Previo (FECOVI), titular de todas las imágenes de la contribución 


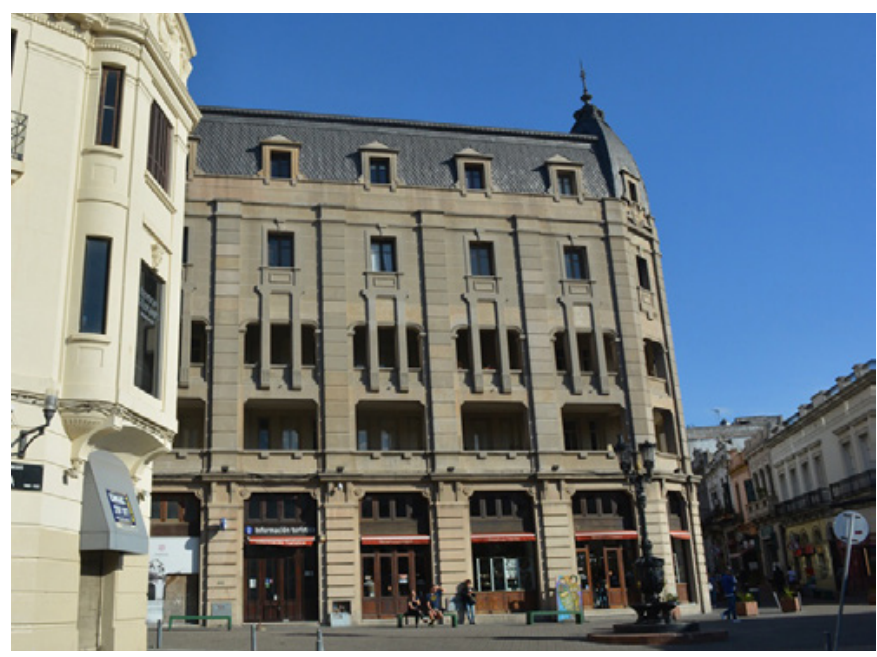

Cooperativa el Resorte, edificio Jaureguiberry (Ciudad Vieja, Montevideo)

Extendiendo este sistema a otros sectores de la ciudad, recientemente se ha puesto en marcha un proyecto de cooperativa dispersa de inmuebles abandonados. Esta iniciativa parte de un acuerdo entre FUCVAM y entidades nacionales, municipales, universitarias y barriales. La propuesta presenta una planificación colaborativa sobre algunos usos sociales para inmuebles vacíos del centro de la ciudad, constituyéndose en una posible política habitacional de gran escala para revitalizar diversas áreas compensando desigualdades de acceso al suelo. Los usos sociales planteables (viviendas, actividades económicas y usos cívicos) son parte de un proyecto mayor para identificar un programa de usos variados (públicos y privados), en la recuperación de inmuebles abandonados, deteriorados y deudores en toda la ciudad. Estos inmuebles constituyen en la actualidad vacíos urbanos, que conforman focos de deterioro urbano general asociado a las problemáticas relativas al abandono como riesgo edilicio, deterioro ambiental, fragmentación social e inseguridad. La cooperativa dispersa supone una innovación del sistema cooperativista, que busca atender nuevas demandas en las formas de habitar y pensar usos mixtos, con espacios que ofrezcan nuevas funciones para la ciudad (GOÑI, 2019).

La aplicación de esta política habitacional como estrategia frente al despoblamiento genera ciertos interrogan- tes... ¿puede consolidarse el sistema de cooperativas en la Ciudad Vieja como una alternativa para afrontar esta problemática de los centros históricos articulando el patrimonio cultural con la política de vivienda?

La disminución poblacional de los centros históricos asociada al deterioro físico de estas áreas requiere de políticas de protección patrimonial integrales, no aisladas. ¿Serán capaces las cooperativas de abordar la complejidad de la situación edilicia, conjuntamente con políticas sociales, educativas y económicas que fomenten la integración de los diversos aspectos, superando la escala del centro histórico e involucrando a toda la ciudad? Su ampliación de escala a través del proyecto de cooperativa dispersa para la recuperación de inmuebles abandonados, ¿permitirá la integración social y física de conjunto?

El avance del fenómeno de la gentrificación-turistificación-exclusión se presenta como uno de los principales retos a afrontar ante intervenciones que logran revitalizar y poner en valor sectores urbanos dotados de un gran valor histórico-patrimonial. ¿Logrará este tipo de actuaciones aportar un haz de luz ante el gran desafío que representa plantear un límite al despoblamiento y poner un freno a la gentrificación?

Dado que los mismos habitantes son quienes trabajan en la recuperación o construcción de los inmuebles, ¿fortalecerá este sistema la concienciación, apropia-

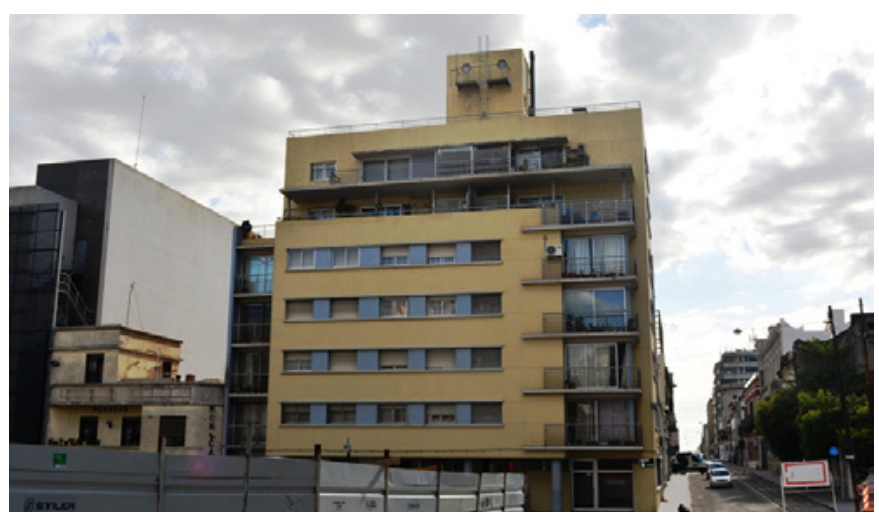

Cooperativa Irupé (Ciudad Vieja, Montevideo) 
a debate ¿Hay patrimonio sin comunidad? Despoblamiento, turistificación y patrimonio cultural

| coordina Jaime Jover Báez

ción y valoración del patrimonio construido de los centros históricos? En esta misma línea, la capacitación de los cooperativistas y el trabajo en equipo, ¿contribuirá a fomentar la identidad y el sentido de pertenencia de los habitantes y a reforzar los lazos entre vecinos impulsando la integración o, por el contrario, contribuirá a generar tensiones entre los residentes?

Por otra parte, la recuperación poblacional del centro histórico debería promover el desarrollo del patrimonio inmaterial. ¿Conseguirá esta política potenciar tradiciones, costumbres y manifestaciones socio-culturales propias del centro histórico o comunes a los habitantes del resto de la ciudad?

Dado que el incremento de habitantes conlleva a su vez la necesidad de incorporación o refuncionalización de edificaciones para usos complementarios al uso residencial (comercial, educativo, de salud, recreativo, cultural, administrativo), ¿podrán garantizar las cooperativas la vitalidad del sector -mediante la multifuncionalidad-, erradicando problemáticas sociales asociadas al abandono y favoreciendo la seguridad ciudadana?

Una de las grandes fortalezas del sistema de cooperativas para llevar adelante sus objetivos ha radicado en la posibilidad de continuidad y permanencia por décadas, atravesando distintos periodos políticos, lo que le ha permitido afianzarse, perfeccionarse, y posicionarse con el paso del tiempo. En este sentido, la ausencia de continuidad, ¿limita y/o frustra a las cooperativas como una alternativa para alcanzar una vivienda digna?

Finalmente, la problemática habitacional y las situaciones sociales que han impulsado el desarrollo de políticas de vivienda con base en cooperativas en la Ciudad Vieja de Montevideo se verifican en numerosos centros históricos a nivel mundial. Esta experiencia, ¿resulta por lo tanto un faro para la profundización y adaptación a otros centros históricos, en el marco del desarrollo de políticas de vivienda que atiendan a estas necesidades, teniendo siempre presente las particularidades y realidades de los diferentes contextos?

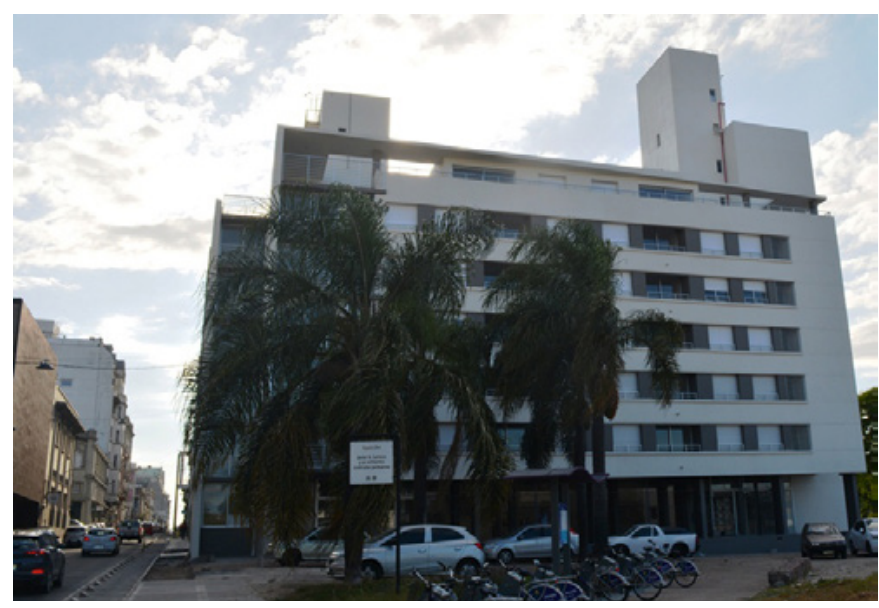

Cooperativa Puerto Fabini (Ciudad Vieja, Montevideo)

\section{BIBLIOGRAFÍA}

- VALENZUELA, K. (2018) El cooperativismo de vivienda uruguayo: cinco décadas construyendo comunidades urbanas. Copublicado entre Subversiones (México) y Resumen (Chile). 13 junio $2018<$ https://subversiones.org/archivos/132559> [Consulta: 21/06/2019]

- GOÑI, A. (2019) Ganar el derecho a la ciudad: hacia un programa de usos de inmuebles abandonados. Posturas. Revista digital La diaria, 20 de marzo de 2019 <https:// ladiaria.com.uy/articulo/2019/3/ganar-el-derecho-a-la-ciudadhacia-un-programa-de-usos-de-inmuebles-abandonados/> [Consulta: 21/06/2019] 